\title{
Identifying the chaîne opératoire of prehistoric clay figurines using experimental archeology and imaging methods
}

\author{
Theodor Ignat \\ University of Bucharest, Bd. M. Kogălniceanu 36-46, Bucharest 050107, Romania \\ theodor_ignat@yahoo.com \\ Roxana Bugoi \\ Horia Hulubei National Institute for Nuclear Physics and Engineering, 30 Reactorului Street, \\ Măgurele 077125, Romania \\ bugoi@nipne.ro \\ Florin Constantin \\ Horia Hulubei National Institute for Nuclear Physics and Engineering, 30 Reactorului Street, \\ Măgurele 077125, Romania \\ fconst@nipne.ro \\ Valentin Parnic \\ Lower Danube Museum, 4 Progresului Street, Călăraşi 910079, Romania \\ vgumelnita@yahoo.com \\ Cătălin Lazăr \\ University of Bucharest, Bd. M. Kogălniceanu 36-46, Bucharest 050107, Romania \\ acltara@yahoo.com \\ Published 10 July 2018
}

\begin{abstract}
This paper reports the use of experimental archaeology and imaging methods-X-ray computed tomography (CT) and radiography - that were employed to decipher the manufacturing techniques of Eneolithic clay artefacts. This study was triggered by the archaeological research conducted in some tell settlements in Southeastern Romania that belong to the Kodjadermen-GumelniţaKaranovo VI culture (c. 4500-3900 BC). The findings reported here represent the first accounts of a recently started research project, which has as its main goal the re-creation of Eneolithic clay artefacts and the identification of the chaîne opératoire used for manufacturing these objects. In particular, X-ray imaging techniques were used as complementary methods to help understand the structure of intact Eneolithic artefacts. In a subsequent step of this research, these techniques will be employed to check for similarities between the archaeological items and modern pottery replicas created in experimental archaeology workshops.
\end{abstract}

Keywords: Chaîne opératoire; archaeological clay items; Eneolithic; X-ray computed tomography; experimental archaeology.

PACS numbers: 07.90.+c, 07.05.Pj

This is an Open Access article published by World Scientific Publishing Company. It is distributed under the terms of the Creative Commons Attribution 4.0 (CC-BY) License. Further distribution of this work is permitted, provided the original work is properly cited. 


\section{Introduction}

This paper reports the use of experimental archaeology and imaging methods - X-ray computed tomography (CT) and radiography_in a trial to identify the manufacturing techniques of Eneolithic clay figurines.

Inspired by the archaeological research at the Sultana-Malu Roșu (Southeastern Romania) tell settlement belonging to the Kodjadermen-Gumelniţa-Karanovo VI culture (KGK VI), dated c. 4500-3900 BC, a project in experimental archaeology was started in $2010 .^{1,2}$ One of the main goals of this project was to re-create Eneolithic clay artefacts. To reach this goal, a complex approach involving the use of archaeometric methods was employed.

The reconstruction of the chaîne opératoire of archaeological pottery started with the information acquired through macroscopic observations. The next step was the development of experimental and demonstrative models. In this process, several types of clay and tempering, modeling, burnishing, decorating, drying and firing procedures were tested. Different hand-making techniques, such as shaping the vessels from one lump of clay, coiling, or molding, were also tried.

The experimental archaeology procedures were backed up by the petrographic (optical microscopy on thin sections) and chemical (X-ray fluorescence and X-ray diffraction) analyses on ceramic samples. These analyses not only led to the identification of the clay sources used as raw material by the prehistoric potters, sources that turned out to be located in the proximity of the tell settlement, but also provided a more refined recipe for the clay-temper mixture. ${ }^{3}$

Imaging using X-ray methods, such as radiography and X-ray computed tomography (X-ray CT) are an excellent noninvasive approach for studying prehistoric clay artefacts, being especially relevant for investigating the structure of unbroken objects.

X-ray CT scans were employed to study the structure of several Eneolithic anthropomorphic and zoomorphic figurines discovered in two tell settlements from Southeastern Romania (see Fig. 1). In a future stage of this on-going project, the set of images obtained of archaeological clay items will be compared to the ones taken of vessels produced during experimental archaeology workshops.

It is expected that the findings of this interdisciplinary project will be useful for future research on other archaeological clay artefacts assemblages. In the long run, it is hoped that they will lead to a better understanding of prehistoric clay items: how they were made, why and for what purpose, and, more importantly, the people who created them.

\section{Experimental Archaeology}

Experimental archaeology was born of necessity. The lack of alternative sources of information is a feature of prehistoric archaeology and has generated over time multiple attempts to reconstruct different objects and processes. The goal of any experimental archaeology approach is to reveal the hidden information behind the objects, what 




Fig. 1. Location of the tell settlements mentioned in the text (1 Măriuţa, 2. Sultana-Malu Roşu, and 3. Cuneşti) and the KGK VI area.

gestures and actions led to their existence, and how much time was needed for their production. In the end, everything is about getting closer to the people who produced these artefacts and understanding more about their way of living.

Experimenting with clay objects is a complex process that we have improved over the past six years; this activity is the core of an ongoing research project. We searched for the most probable clay sources that the prehistoric community from Sultana-Malu Roşu might have used, and we identified them no further than $1 \mathrm{~km}$ away from the tell settlement. To reach this conclusion, burnt clay samples from several nearby clay sources were analyzed using petrographic (optical microscopy on thin sections) and chemical (Xray fluorescence and X-ray diffraction) methods, and the results of these measurements were compared to the ones of pottery from the settlement. ${ }^{3}$ Thus, we found out more about the clay recipe and have used this information in our experiments. In all cases, raw 
clay was mixed with grog (crushed pottery) in proportions ranging from $15 \%$ to $25 \%$. In modeling the clay objects, we used a wide range of tools, from natural ones, such as reed straw, pebbles, strands of hair, and sheep skin, to more elaborate ones, such as wood and bone spatulas. We have also experimented with several modeling techniques (Fig. 2). Shaping clay objects from one lump of clay, coiling, and molding of vessels were pursued. Some objects require several stages of modeling, which means partial drying takes place between stages; junctions were kept wet using leaves, so that work could resume on the object. The same technique was used when modeling pots from two separate halves. Drying took place outside in the shade with no control over the temperature and humidity. Even so, we have successfully produced clay objects and vessels that made it to the firing stage (Fig. 2). Different types of kilns and pit firing were tested. Depending on the firing structure, we have achieved temperatures ranging from $285^{\circ} \mathrm{C}$ to $850^{\circ} \mathrm{C}$, using as fuel between $0.25 \mathrm{~m}^{3}$ and $0.75 \mathrm{~m}^{3}$ of straw, elm, or any piece of dry wood that we could gather from nearby the settlement. The whole process, from harvesting the clay to burnt-clay artefacts, took no more than two weeks and involved five to six persons.


Fig. 2. The experimental archaeology approach for modeling clay vessels: (1) producing grog by crushing sherds, (2) mixing the clay with the grog, (3) intermediate stages of modeling a vessel, (4) modeling a vessel from two separate halves, (5) drying the pots in the shade, and (6) firing the vessels in the kiln.

\section{X-Ray Tomographic Device and Experimental Procedures}

During the last few decades, imaging methods such as radiography and X-ray CT have been increasingly applied in archaeological research. ${ }^{4-17}$ These techniques reveal details about the internal structure of the artefacts that cannot be otherwise discovered except through destructive investigations. If the inner structure of an object can be determined, speculations about the way it was manufactured, as well as about the roles it might have played can be put forward. 
Generally speaking, X-ray CT machines are built according to the type of application for which they are to be used. The X-ray tomographic device and the software implementing the image-reconstruction algorithm were developed especially for archaeometric studies at the Horia Hulubei National Institute for Nuclear Physics and Engineering, Măgurele. ${ }^{14}$ This X-ray CT apparatus was designed for imaging cultural heritage artefacts made out of low-Z materials, e.g., ceramic, bone, and wood. It comprises a compact X-ray source from Spellman High Voltage Electronics Corporation (160 kV maximum X-ray tube voltage, $3 \mathrm{~mA}$ maximum current intensity), a homemade positioning system capable of rotation and translation movements under computer control, and a Varian PaxScan ${ }^{\circledR}$ flat panel detector with large dimensions $\left(40 \times 30 \mathrm{~cm}^{2}\right)$. This amorphous silicon detector (127 mm pixel pitch) was engineered for high-speed radiographic imaging. The spatial resolution of this CT device is roughly $300 \mu \mathrm{m}$. This device can be used to investigate relatively small objects with a maximum volume of $\sim 20$ $x 20 \times 20 \mathrm{~cm}^{3}$. To realize image reconstruction, homemade software based on a modified Filtered Back Projection algorithm was also developed. The X-ray tube working parameters were optimized for the tomography of ceramic artefacts, namely a tube voltage of $70 \mathrm{kV}$ and a current intensity of $700 \mu \mathrm{A}$. The entire volume of each artefact was scanned in 120 steps, representing a full rotation of the object around its central axis. The partial images were summed to obtain the final projection. The acquisition time for a full tomographic scan was roughly $5 \mathrm{~min}$, and the image reconstruction took approximately $4 \mathrm{~min}$. Investigations on archaeological ceramic artefacts employing this CT device were reported in Refs. 14-17.

\section{Results}

The results of archaeological experiments from Sultana-Malu Roşu can be also applied to similar discoveries in contemporary settlements belonging to the same KGK VI culture (see Fig. 1). The results of the imaging using X-ray CT scans reported in this paper were performed on several anthropomorphic and zoomorphic figurines discovered in two other KGK VI tell settlements in Southeastern Romania, contemporary with Sultana-Malu Roşu.

\subsection{Bird-shaped figurine from Cuneşti}

This zoomorphic figurine (Inventory Number 12625) belongs to the Lower Danube Museum, Călăraşi County, Romania. It was discovered at the Cuneşti tell settlement in a context attributed to the KGK VI communities. The ceramic paste is brown and sandy, and the object has a rough surface. The figurine (shown in Fig. 3, left) is $3.7 \mathrm{~cm}$ tall, 4.5 $\mathrm{cm}$ from head to tail, and has a wingspan of $6.2 \mathrm{~cm}$. This object is the representation of a bird on top of a pedestal represented by the bird legs. The wings have sharp tips pointing downwards. The head is flat and it points upwards. All these features are characteristic of a flightless bird. No decoration is present on the object. 



Fig. 3. Bird-shaped figurine from the Cunești tell settlement (Romania): (left) photo (scale length $5 \mathrm{~cm}$ ) and (center and right) $\mathrm{CT}$ scan images with arrows indicating the enclosed clay balls.

The body of the bird is hollow, and if shaken, a sound is produced by several internal bodies. Consequently, this item can be identified as a rattle. Macroscopic examination of the object and the rattle sound suggest that the body was made from separately modeled pieces that were subsequently assembled together.

The tomographic scans (Fig. 3, center and right) revealed four balls enclosed in this ceramic object. The density of these inner objects seems to not be very different from that of the object itself, meaning that the balls were also made from clay, probably partially burnt before enclosure. Moreover, the X-ray image shows the inner profile of the bird body, with an uneven lower part and a thin, smooth upper part.

\subsection{Bird-shaped figurine from Măriuța}

Another bird-shaped figurine (Inventory Number 43251) belonging to the KGK VI culture was discovered in the destruction level of dwelling no. 3 from the Măriuţa tell settlement. The object (shown in Fig. 4, left) is $4.4 \mathrm{~cm}$ tall and it spans $3.8 \mathrm{~cm}$ from head to tail; it is a representation of a flightless bird on a cylindrical pedestal. The ceramic paste is smooth and was tempered with a small amount of grog. It was burnt in an oxidizing atmosphere and consequently has a light-brown color, but the core is black due to incomplete firing. The head and the tail are pointing upwards, while the wings are horizontally placed and inclined similarly to airplane wings.

The X-ray tomographic scans (Fig. 4, right) reveal a homogenous paste with a small amount of foreign constituents in the clay matrix. Between the body and the pedestal, a slight anomaly is visible, representing an air pocket and suggesting that these parts have been separately modeled and subsequently joined together.

\subsection{Zoomorphic figurine from Măriuţa}

Discovered in the same tell settlement of Măriuța, this zoomorphic figurine (Inventory Number 24277) represents a mammal (see Fig. 5). It has an elongated shape $(1.9 \mathrm{~cm}$ tall and $5.3 \mathrm{~cm}$ long), four small legs, rounded tail, small ears made by pinching, and a supersized head pointing downwards. The head is perforated on an oblique trajectory from neck to mouth and it is so big that when the object is placed in normal position, the front legs are not touching the ground. Zoomorphic figurines with this type of head 
perforation are characteristic of the KGK VI culture. The ceramic paste is grayish, having a smooth surface.
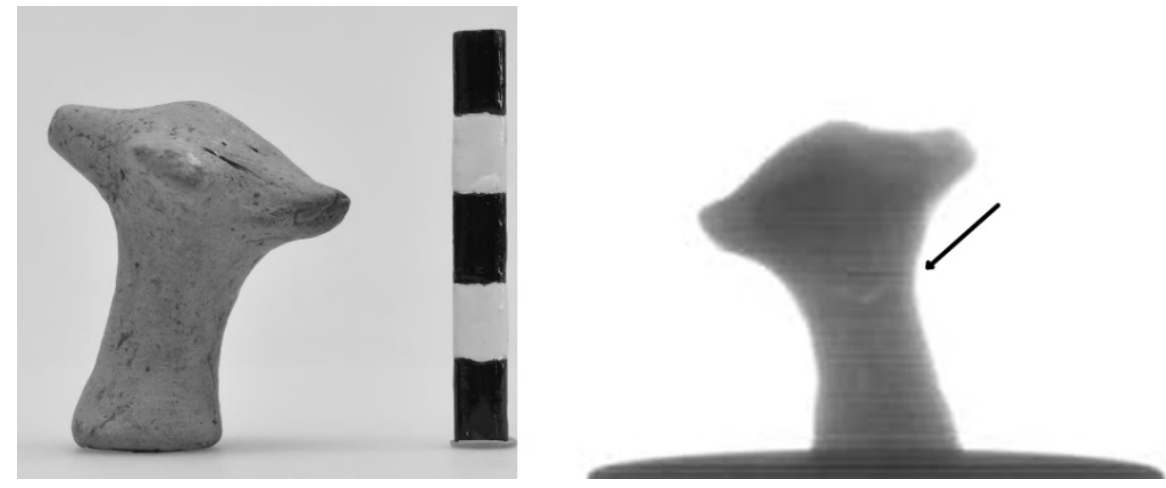

Fig. 4. Images of the bird-shaped figurine from Măriuța tell settlement (Romania): (left) photo (scale length $5 \mathrm{~cm}$ ) and (right) CT scan image, with an arrow indicating the junction between the body the pedestal.



Fig. 5. Images of the zoomorphic figurine from Măriuța tell settlement (Romania): (left) photo (scale length $5 \mathrm{~cm}$ ) and (right) $\mathrm{CT}$ scan image with arrow indicating the junction between the head and the body.

The X-ray tomographic scans (Fig. 5, right) clearly reveal the already visible perforation, but in addition they show that the edges of the perforation converge from neck to mouth, suggesting the use of a pointy tool, rather than a stick, to make it. The head is a shade lighter that the rest of the body, suggesting that it has been made from a clay piece distinct from the torso and tail. No foreign constituents were distinguished in the clay matrix.

\subsection{Anthropomorphic figurine from Măriuţa}

This anthropomorphic figurine (Inventory Number 42290) was discovered in the upper level of the tell settlement of Măriuța in dwelling no. 1 (US 1009-distruction) and belongs 
to the same KGK VI culture. It was made from a homogenous paste, tempered with a small amount of organic matter. The almost white exterior is roughly smoothed and the core is dark gray due to incomplete firing. The head is now missing, the figurine is 5.4 $\mathrm{cm}$ tall and it has an arm span of $4.7 \mathrm{~cm}$ (see Fig. 6). Anatomical features such as breasts, buttocks, and hips are well individualized; on the back the figurine bears a hump. ${ }^{18}$ The hips are unevenly distributed, the left one being lower than the right one, giving the impression of a person that is leaning on one foot. These features suggest that this figurine represents an old or sick woman.


Fig. 6. Images of the anthropomorphic figurine from Măriuța tell settlement (Romania): (left) photos (scale length $5 \mathrm{~cm}$ ) and (right) slice from the CT scan. The arrows indicate the junction between the arms and the body.

The X-ray CT scan (Fig. 6, right) reveals that the manufacturing took place in at least two separate stages. Thus, the body with all the above-mentioned anatomical features was probably manufactured first, and the arms were subsequently added. Small vertical voids, lighter in color, separate the arms from the body.

\subsection{Anthropomorphic figurine from Măriuța}

This item (shown in Fig. 7) is from Măriuța tell settlement and has probably the most fascinating story. It was found in the upper levels of the KGK VI settlement, in a tworoom dwelling (House no. 2). It was made from a homogenous paste without temper. The figurine (Inventory Number 43158) is $9.7 \mathrm{~cm}$ tall and has an arm span of $6.7 \mathrm{~cm}$. The body is almost rectangular; the arms are perforated and placed horizontally. On the back, two small applied protuberances represent the buttocks. On the front, small breasts were pinched from the body; the pubic area is represented by an incised triangle. Other incisions embellishing the body may represent clothing. The rhomboidal head is highly decorated. Each ear is perforated in four points; the eyes are outlined by two horizontal incisions and the mouth by four dimples, subsequently filled with a white paste. The head of the restored figurine was discovered on the floor of room no. 1, $7 \mathrm{~m}$ away from the body that was found next to the hearth in room no. 2. The lack of wear traces around the fracture indicates an intentional breakage and separate placement of these two pieces. ${ }^{19}$ 

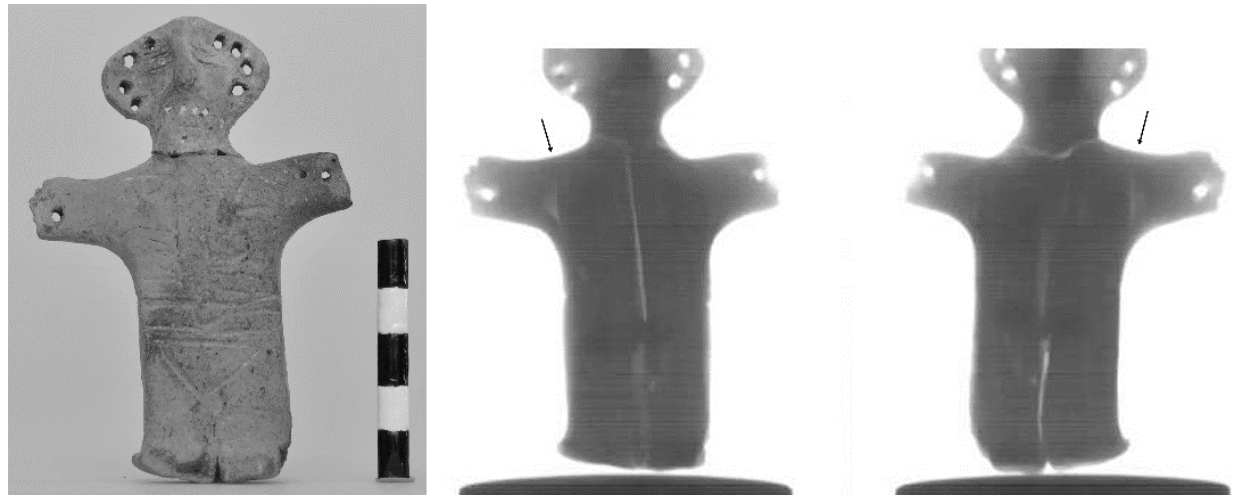

Fig. 7. Image of the anthropomorphic figurine from the Măriuța tell settlement (Romania): (left) photo (scale length $5 \mathrm{~cm}$ ); (center) front view and (right) back view are CT scan images. The arrows indicate the junction between the arms and the body.

The X-ray tomographic scans (Fig. 7, center and right) indicate that maybe this occurence was foreseen by the makers of this artefact. A white vertical line splits the body of this item in two. There are also visible marks suggesting that the arms were a later addition. We suspect that the head was modeled separately from the rest of the body, but the crack masks such evidence on the tomographic image.

\section{Conclusions}

The X-ray imaging investigations reported in this paper were used to reveal the structure of several Eneolithic anthropomorphic and zoomorphic figurines discovered at the Cuneşti and Măriuţa tell settlements (Southeastern Romania), while the experimental archaeology procedures were employed to produce modern replicas of ancient potteries with the goal of reconstructing the steps of the chaîne opératoire employed in making these prehistoric clay items. The X-ray imaging investigations have a special relevance for the archaeological research, helping to understand the structure of these ancient objects, the way in which they were manufactured, and to suggest hypotheses about the role they played. At this stage of the project, we have used X-ray CT to analyze more than forty Eneolithic clay items, out of which we chose to present only five in this paper. For all of the artefacts reported in this article, we have noticed the practice of modeling the clay figurines in more than one stage; several parts of the same object were separately made and then joined together. We consider this practice to be of special significance, considering that the rest of the imaged artefacts have not yielded any manufacturing feature worth mentioning: they all seem to have been made from one lump of clay, some of them being more homogenous than others.

This on-going archaeometric project is expected to lead to an accurate reconstruction of the manner in which Eneolithic clay artefacts were produced, shedding new light on the life of our ancestors. 


\section{Acknowledgments}

This work is supported by a CNCS-UEFISCDI grant, project number PN-III-P2-2.1PED-016-0742.

\section{References}

1. T. Ignat, V. Opriș, C. Lazăr, Buletinul Muzeului Judeţean Teleorman 5, 151 (2013).

2. C. Lazăr, Buletinul Muzeului Județean Teleorman 7, 193 (2015).

3. T. Ignat, A. Luca, D. Dimofte, C. Lazăr, F. Constantin and R. Bugoi, submitted to Archaeosciences/Revue d'Archeometrie, Proceedings of the EMAC 2017 conference.

4. F. Casali, Archaeometriai Mühely 1, 24 (2006).

5. M. Ghysels, Art Tribal 4, 116 (2003).

6. K. Haneca, K. Deforce, M. N. Boone, D. Van Loo, M. Dierick, J. Van Acker and J. Van Den Bulcke, Archaeometry 54, 893 (2012).

7. L. Harvig, N. Lynnerup and J. Amsgaard Ebsen, Archaeometry 54, 369 (2012).

8. E. Lehmann, E. Deschler-Erb, E and A. Ford, Archeometry 52, 272 (2010).

9. C. Tuniz, F. Bernardini, I. Turk, L. Dimkaroski, L. Mancini and D. Dreoss, Archeometry 54, 581 (2012).

10. M. P. Morigi, F. Casali, M. Bettuzzi, R. Brancaccio and V. D’Errico, Appl. Phys. A100, 653 (2010).

11. C. Tuniz, F. Bernardini, A. Cicuttin, M. L. Crespo, D. Dreossi, A. Gianoncelli, L. Mancini, A. Mendoza Cuevas, N. Sodini, G. Tromba, F. Zanini and C. Zanolli, Nucl. Instr. Meth. A711, 106 (2013).

12. A. Re, F. Albertin, C. Avataneo, R. Brancaccio, J. Corsi, G. Cotto, S. De Blasi, G. Dughera, E. Durisi, W. Ferrarese, A. Giovagnoli, N. Grassi, A.Lo Giudice, P. Mereu, G. Mila, M. Nervo, N. Pastrone, F. Prino, L. Ramello, M. Ravera, C. Ricci, A. Romero, R. Sacchi, A. Staiano, L. Visca and L. Zamprotta, Heritage Science 2, 19 (2014).

13. M. Sanger, J. Arch Sci: Reports 9, 586 (2016).

14. F. Constantin, C. Pavel, R. Bugoi and M. Toderaş, Nucl. Instr. Meth. A621, 685 (2010).

15. C. Pavel, C. Suciu, F. Constantin and R. Bugoi, Documenta Praehistorica XL, 323 (2013).

16. C. Pavel, F. Constantin, C.I. Suciu and R. Bugoi, in Proc. 39th Int. Symp. Archaeometry, eds. R. B. Scott, D. Braekmans, M. Carremans and P. Degryse (2014), p. 193.

17. C. Pavel, F. Constantin, C.I. Suciu and R. Bugoi, Int. J. Modern Phys. Conf. Series 27, 1460135-1 (2014).

18. V. Parnic and C. Lazăr, In Honorem Silvia Marinescu-Bilcu 70 de ani, Cultura și Civilizatie la Dunarea de Jos XXII, 358 (2005).

19. V. Parnic and C. Lazăr, In Honorem Silvia Marinescu-Bilcu 70 de ani, Cultura și Civilizatie la Dunarea de Jos XXII, 357 (2005). 